\title{
Graphene-enhanced metal oxide gas sensors at room temperature: a review
}

Dongjin Sun ${ }^{1}$, Yifan Luo ${ }^{1}$, Marc Debliquy ${ }^{2}$ and Chao Zhang ${ }^{* 1}$

\author{
Review \\ Address: \\ ${ }^{1}$ College of Mechanical Engineering, Yangzhou University, Yangzhou \\ 225127, China and ${ }^{2}$ Department of Materials Science, University of \\ Mons, 7000 Mons, Belgium \\ Email: \\ Chao Zhang* - zhangc@yzu.edu.cn \\ ${ }^{*}$ Corresponding author \\ Keywords: \\ gas sensor; graphene; metal oxide; nitrogen dioxide (NO2); room \\ temperature
}

Beilstein J. Nanotechnol. 2018, 9, 2832-2844.

doi:10.3762/bjnano.9.264

Received: 31 August 2018

Accepted: 25 October 2018

Published: 09 November 2018

Associate Editor: N. Motta

(C) 2018 Sun et al.; licensee Beilstein-Institut. License and terms: see end of document.

\begin{abstract}
Owing to the excellent sensitivity to gases, metal-oxide semiconductors (MOS) are widely used as materials for gas sensing. Usually, MOS gas sensors have some common shortages, such as relatively poor selectivity and high operating temperature. Graphene has drawn much attention as a gas sensing material in recent years because it can even work at room temperature, which reduces power consumption. However, the low sensitivity and long recovery time of the graphene-based sensors limit its further development. The combination of metal-oxide semiconductors and graphene may significantly improve the sensing performance, especially the selectivity and response/recovery rate at room temperature. In this review, we have summarized the latest progress of graphene/metal-oxide gas sensors for the detection of $\mathrm{NO}_{2}, \mathrm{NH}_{3}, \mathrm{CO}$ and some volatile organic compounds (VOCs) at room temperature. Meanwhile, the sensing performance and sensing mechanism of the sensors are discussed. The improved experimental schemes are raised and the critical research directions of graphene/metal-oxide sensors in the future are proposed.
\end{abstract}

\section{Review \\ Introduction}

Since the discovery by Novoselov and Geim [1], graphene has been widely used in various fields such as photocatalysts, lithium battery electrodes, supercapacitors, gas sensors and electronic devices [2-4] due to its high specific surface area $\left(2630 \mathrm{~m}^{2} / \mathrm{g}\right)$ and high carrier mobility at room temperature [5]. The electrical properties of graphene are easily affected by the adsorption of gas molecules at room temperature. Thus, graphene has a promising future in the application in gas sensors. Schedin et al. [2] studied the gas sensing performance of graphene for the first time in 2007 and claimed that the adsorption of gas molecules caused a gradual change in graphene resistance via altering the local carrier concentration. After that, a wave of research regarding graphene has been set off. 
The mass production of single-layered graphene is difficult. Another problem is that pristine graphene does not have a bandgap, which means it is not suitable for semiconductor gas sensors [6]. Graphene oxide (GO), as a derivative of graphene, is prepared via the oxidation of graphene. Epoxy groups, hydroxy groups and defects are produced at the surface when oxidizing graphene [7-10]. These variations will alter the electronic structure of graphene, thus converting it to a semiconductor. Choi et al. [11] prepared GO room-temperature gas sensors by a modified Hummers method. The group found that the sensitivity and repeatability of the sensor depended on the amount of oxygen functional groups on the surface of GO. Moreover, hydroxy groups were the key to provide GO with semiconducting properties. However, an excessive presence of functional groups will make GO an insulating material [12]. In addition, it is difficult to control the content of oxygen functional groups during the process of oxidation, indicating that GO is not an appropriate gas-sensing material. Therefore, further reduction of GO is necessary and the product after reduction is called reduced graphene oxide (rGO). Some oxygen functional groups remain after the reduction, some defects and vacancies are generated during the reduction, which are beneficial for the gas adsorption [13]. The oxygen functional groups that locate on the surface of rGO lead to an electron transfer from rGO to oxygen functional groups, and holes become the main charge carriers, indicating that rGO acts as a p-type semiconductor [14-16]. Zhang et al. [17] prepared rGO room-temperature gas sensor with porous structure and defects for detecting $\mathrm{NO}_{2}$. The sensor showed high sensitivity to $\mathrm{NO}_{2}$ at low concentrations. In another work, Hu et al. [18] fabricated an ultra-sensitive $\mathrm{rGO}$ gas sensor, which reached a response of $2.4 \%$ to $1 \mathrm{ppb} \mathrm{NH}_{3}$ with an ultra-fast response time of $1.4 \mathrm{~s}$ at room temperature. The sensors based on $\mathrm{rGO}$ exhibited a rapid and high response to target gas at room temperature. However, these sensors show a common shortage. Since the binding force between graphene and gas molecules is van der Waals force or even covalent bonds [6], the recovery time is too long, sometimes recovery is not achieved at all $[19,20]$.

Metal-oxide semiconductors (MOS), including tin oxide $\left(\mathrm{SnO}_{2}\right)$, titanium dioxide $\left(\mathrm{TiO}_{2}\right)$, zinc oxide $(\mathrm{ZnO})$, copper oxide $(\mathrm{CuO})$, tungsten oxide $\left(\mathrm{WO}_{3}\right)$, indium oxide $\left(\mathrm{In}_{2} \mathrm{O}_{3}\right)$, ferric oxide $\left(\mathrm{Fe}_{2} \mathrm{O}_{3}\right)$ and cobalt oxide $\left(\mathrm{Co}_{3} \mathrm{O}_{4}\right)$ are important materials for gas sensors [21-28]. These types of materials possess many exceptional advantages, such as high sensitivity, rapid response/recovery times and low cost. Until now, there is no unified definition of the mechanism of MOS gas sensors. The most widely accepted oxygen-adsorption theory is described as follows [29]: oxygen molecules capture electrons from semiconductors to form oxygen anions when the sensor is exposed to air, and the operating temperature affects the forms of oxygen anions. When the operating temperature is below $147^{\circ} \mathrm{C}$, the oxygen anions are mainly $\mathrm{O}_{2}^{-}$. With the increase of temperature, $\mathrm{O}_{2}{ }^{-}$is transformed into $\mathrm{O}^{-}$. When the temperature is above $397{ }^{\circ} \mathrm{C}$, the oxygen anions are converted into $\mathrm{O}^{2-}$. The reaction equations are as follows:

$$
\begin{gathered}
\mathrm{O}_{2}(\text { gas }) \longrightarrow \mathrm{O}_{2}(\text { ads }) \\
\mathrm{O}_{2}(\text { ads })+\mathrm{e}^{-} \longrightarrow \mathrm{O}_{2}^{-} \\
\mathrm{O}_{2}(\text { ads })+2 \mathrm{e}^{-} \longrightarrow 2 \mathrm{O}^{-} \\
\mathrm{O}_{2}(\text { ads })+4 \mathrm{e}^{-} \longrightarrow 2 \mathrm{O}^{2-}
\end{gathered}
$$

For n-type semiconductors, the electrons will continue to be captured from the surface of the semiconductors so that the width of electron depletion layer increases when exposed to oxidizing gases, increasing the electrical resistance. The gas molecules act as electron donors to the semiconductors when exposed to reducing gases, meaning that the width of electron depletion layer decreases, which decreases the resistance of the sensor. For p-type semiconductors, the width of hole accumulation layer increases by capturing electrons from the surface of semiconductors when exposed to oxidizing gases, causing the resistance to decrease. The electrons are released into the semiconductor to decrease the width of hole accumulation layer when exposed to reducing gases, which increases the resistance of the sensor. The sensing performances of MOS sensors are heavily affected by the working temperature, because the working temperature influences the kinetics, conductivity and electron mobility of MOS [30,31]. Since sufficient thermal energy is required to overcome the potential barrier and achieve the required electron mobility, the operating temperature of MOS sensors is above $200{ }^{\circ} \mathrm{C}$ in general. The excessive operating temperature leads to high power consumption and difficulty of integration, which is contrary to our concept of energy conservation and emission reduction. Moreover, sensors working in flammable and explosive environments at a high temperature may cause fire or explosion. Also, operating at high temperature causes sensor instabilities, which lead to incorrect measurements [32-34]. Therefore, current research focuses on reducing the operating temperature of MOS gas sensors.

Modifications of composition and surface, and light illumination of MOS are effective ways to improve their gas-sensing performance. MOS composites with graphene or its derivatives 
can reduce the operating temperature and yield outstanding sensing performance surpassing that of the single components. The mechanisms through which graphene enhances the sensing performance of MOS sensors will be interpreted in the following sections. Wang et al. [35] reported that a formaldehyde (HCHO) sensor based on $\mathrm{SnO}_{2}-\mathrm{GO}$ composites, fabricated via electrospinning, exhibited a three times higher sensitivity than that of the pure $\mathrm{SnO}_{2}$ sensor at $120^{\circ} \mathrm{C}$. The composite sensor was able to detect $500 \mathrm{ppb} \mathrm{HCHO}$. The unique sensing properties of $\mathrm{SnO}_{2}-\mathrm{GO}$ sensor was interpreted by the large specific surface area, the high number of oxygen functional groups and electric regulation effects provided through the addition of GO. The $\mathrm{ZnO}-\mathrm{rGO}$ sensor reported by Zou et al. [36] showed a sensitivity of 96.4 to $50 \mathrm{ppm}$ ethanol at $260{ }^{\circ} \mathrm{C}$ with short response and recovery times. Extensive research on graphene/metal-oxide sensors has been carried out over the recent years [37-43]. It appears clear that the working temperature of graphene/metal-oxide sensors is lower than that of MOS sensors. In some cases, graphene/metal-oxide sensors were even operated at room temperature.

There are many kinds of toxic gases from industrial processes and car emissions around us, such as $\mathrm{NO}_{2}, \mathrm{NH}_{3}, \mathrm{CO}$ and most volatile organic compounds (VOCs). In general, people should not be exposed to an environment with more than $35 \mathrm{ppm} \mathrm{NH}_{3}$ for more than $15 \mathrm{~min}$ or an environment with more than $10 \mathrm{ppm}$ $\mathrm{CO}$ for more than $10 \mathrm{~min}$. Also, people should not be exposed to workplaces with more than $0.08 \mathrm{ppm}$ formaldehyde for more than 30 min according to World Health Organization [44]. Therefore, there is an urgent need for gas sensors with low cost, outstanding selectivity and sensitivity for detecting these toxic gases [6]. Compared with MOS sensors, graphene/metal-oxide sensors enhance the gas-sensing performance in many aspects, such as sensitivity, response/recovery times and the operating temperature. There are numerous mechanisms for the enhanced gas-sensing performance according to different views of scholars. The most widely accepted mechanisms are: the formation of semiconductor interfaces, a synergetic coupling effect between the two components, and improved morphology and structure due to the introduction of graphene. The following is a review of the recent progress concerning the application of graphene/metal-oxide sensors to discern various toxic gases at room temperature.

\section{Enhancement by the formation of semiconductor interfaces}

Reduced graphene oxide (rGO), which plays the role of a p-type semiconductor, can form heterojunctions when forming composites with most metal-oxide semiconductors. In the example of a $\mathrm{SnO}_{2}-\mathrm{rGO}$ sensor [45], $\mathrm{SnO}_{2}$ and $\mathrm{rGO}$ formed $\mathrm{p}-\mathrm{n}$ heterojunctions. The enhancement mechanism of the $\mathrm{p}-\mathrm{n}$ heterojunction is shown in Figure $1, E_{\mathrm{c}}$ and $E_{\mathrm{v}}$ are the energies of conduction band and valence band of the two components, respectively, while the Fermi level energy $\left(E_{\mathrm{f}}\right)$ is between these two bands. It can be seen from Figure 1 that the work function of rGO is lower than that of $\mathrm{SnO}_{2}$, meaning that electrons transfer from $\mathrm{rGO}$ to $\mathrm{SnO}_{2}$ in the heterojunctions. The Schottky barrier is only $0.2 \mathrm{eV}$ due to the changed Fermi level of the composite structure after achieving a dynamic balance of the electron flow, indicating that the electrons are able to pass through the energy barrier. In summary, the $\mathrm{SnO}_{2}-\mathrm{rGO}$ sensor allow for the transition of electrons even at room temperature because of its low Schottky barrier. When exposed to air at room temperature, oxygen molecules obtain electrons from n-type $\mathrm{SnO}_{2}-\mathrm{rGO}$ hybrids to form $\mathrm{O}_{2}{ }^{-}$. The electron depletion layers generated on the interfaces of $\mathrm{SnO}_{2}$ grains and $\mathrm{rGO}$ sheets owing to the loss of electrons and the resistance is the initial resistance of the sensor. The initial resistance of $\mathrm{SnO}_{2}-\mathrm{rGO}$ sensor is much lower

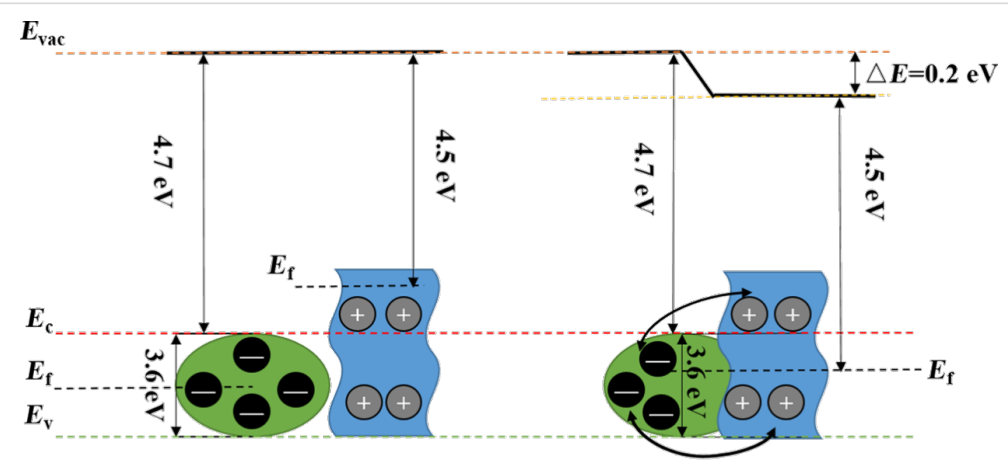

$\mathrm{SnO}_{2}$ 
than that of a $\mathrm{SnO}_{2}$ sensor since because of the high conductivity of rGO, indicating that variations of resistance can be detected at room temperature. Moreover, the electron depletion layers in the $\mathrm{SnO}_{2}-\mathrm{rGO}$ sensor where the electrons are constantly moving between $\mathrm{SnO}_{2}$ and $\mathrm{rGO}$ are wider than those in a $\mathrm{SnO}_{2}$ sensor. When exposed to reducing gases $\left(\mathrm{CO}, \mathrm{NH}_{3}\right.$, most VOCs), the gas molecules act as electron donors to $\mathrm{SnO}_{2}-\mathrm{rGO}$ so that the resistance of composite sensor decreases dramatically, leading to high sensitivity and rapid response.

Isotypical $\mathrm{p}-\mathrm{p}$ homojunctions are formed when $\mathrm{rGO}$ forms composites with most p-type metal-oxide semiconductors. The enhancement mechanism of $\mathrm{p}-\mathrm{p}$ homojunctions is similar to that of $p-n$ heterojunctions. However, $p-n$ junctions cause the recombination of charge carriers with a decreased amount of charge carriers, while $\mathrm{p}-\mathrm{p}$ junctions lead to spatially separated charge carriers with an unchanged amount of charge carriers. The following summarizes the parameters of several room-temperature gas sensors based on $\mathrm{rGO} /$ metal oxides, which exhibit enhanced sensing performance mainly due to the formation of heterojunctions.

Tai et al. [46] deposited $\mathrm{ZnO}$ nanoparticles and GO thin films on gold interdigital electrodes (IDEs) through a simple spray process and thermally reduced the deposits to $\mathrm{ZnO}-\mathrm{rGO}$ composites. The $\mathrm{ZnO}-\mathrm{rGO}$ sensor exhibited a response of 1.2 to $\mathrm{NH}_{3}$ with ultra-fast response/recovery times of $78 \mathrm{~s} / 188 \mathrm{~s}$, which was much better than that of a pure rGO sensor (low response and endless recovery time). The composite sensor with the optimal amount of GO $(1.5 \mathrm{~mL})$ was highly sensitive to low concentrations of $\mathrm{NH}_{3}$ and responded dramatically, which could be ascribed to the $\mathrm{p}-\mathrm{n}$ heterojunctions formed between $\mathrm{ZnO}$ and rGO. However, the influence of humidity on the sensor response was not negligible due to the residual oxygen (high hydrophilicity) on $\mathrm{rGO}$ and the active sites (oxygen vacancies) on $\mathrm{ZnO}$. Chen and co-workers [45] demonstrated that a $\mathrm{SnO}_{2}-\mathrm{rGO}$ sensor, which was synthesized via growing $\mathrm{SnO}_{2}$ nanorods on a GO surface, showed a response of 1.3 to $200 \mathrm{ppm} \mathrm{NH} \mathrm{NH}_{3}$ with instant response/recovery times of only $8 \mathrm{~s} /$ $13 \mathrm{~s}$ at room temperature. The rapid response and particularly the ultra-fast recovery were extremely inspiring because the recovery time of sensors based on rGO is usually long at room temperature. As a comparison, the pure $\mathrm{SnO}_{2}$ sensor is only able to work at $160{ }^{\circ} \mathrm{C}$. The outstanding sensing performance was accounted for by the $\mathrm{p}-\mathrm{n}$ heterojunctions according to the explanation of the authors. $\mathrm{NH}_{3}$ adsorbed on rGO has a smaller adsorption energy than other gases. Strong hydrogen bonds were formed between hydrogen atoms $\left(\mathrm{NH}_{3}\right)$ and the residual oxygen atoms on $\mathrm{rGO}$, facilitating the interaction of $\mathrm{NH}_{3}$ with rGO. Thus the selectivity to $\mathrm{NH}_{3}$ was good. The authors found that water molecules affected the sensor at low humidity levels.
However, the response of the composite sensor increased with increasing humidity at high humidity levels. At low humidity levels, ammonia and water molecules competed for adsorption, which reduces the sensing performance of $\mathrm{NH}_{3}$. As humidity levels increased, ammonia adsorbed on the surface of sensor by dissolving into water, leading to the higher response. This is quite different from the usual opinion that sensitivity will decrease at high humidity levels.

Zhang et al. [47] synthesized $\mathrm{CuO}$ nanoflowers via hydrothermal method, then $\mathrm{CuO}$ and $\mathrm{rGO}$ were deposited on the substrate with $\mathrm{Ni} / \mathrm{Cu}$ IDEs to fabricate the $\mathrm{CuO}-\mathrm{rGO}$ sensor. The $\mathrm{CuO}-\mathrm{rGO}$ sensor showed a three-times higher sensitivity to $\mathrm{CO}$ and faster response/recovery time than the rGO sensor, while the pure $\mathrm{CuO}$ sensor showed no response to $\mathrm{CO}$ at room temperature. The $\mathrm{p}-\mathrm{p}$ junctions constituted between $\mathrm{p}$-type $\mathrm{CuO}$ and rGO contributed to the extraordinary sensing performance. The work function of $\mathrm{CuO}(4.1-4.3 \mathrm{eV})$ and $\mathrm{rGO}(5.0-5.1 \mathrm{eV})$ are not equal $[48,49]$, hence $E_{\mathrm{g} 1}(1.2 \mathrm{eV})$ is not equal to $E_{\mathrm{g} 2}$ $(0.4 \mathrm{eV})[50,51]$. The electrons will transfer from $\mathrm{CuO}$ to $\mathrm{rGO}$ until the Fermi energy level of the two components is equal, which accounts for the improved sensing performance to $\mathrm{CO}$ at room temperature. Wang et al. [52] mixed $\mathrm{ZnO}$ nanowires, prepared via carbothermal reduction, with GO under a protective gas atmosphere (Ar) at $300{ }^{\circ} \mathrm{C}$ to synthesize $\mathrm{ZnO}-\mathrm{rGO}$ hybrids. Although the response to $\mathrm{NH}_{3}$ was not as well as that of a pure $\mathrm{ZnO}$ sensor, the $\mathrm{ZnO}-\mathrm{rGO}$ sensor exhibited rapid response/ recovery times with a detection limit of $50 \mathrm{ppb}$ while the pure $\mathrm{ZnO}$ sensor was unrecoverable at room temperature. The authors stated that the $\mathrm{p}-\mathrm{p}$ junctions constituted $\mathrm{ZnO}$ and $\mathrm{rGO}$ reduced the response/recovery times dramatically. An interesting phenomenon found by the authors was that the pure $\mathrm{ZnO}$ sensor showed characteristics of a p-type semiconductor during the test. Two reasons were given for this. One was that a little carbon and nitrogen might be doped into $\mathrm{ZnO}$ due to the addition of graphite and nitrogen gas protection during the carbothermal reduction $\left(1150^{\circ} \mathrm{C}\right)$. Another was the formation of Schottky barriers between $\mathrm{ZnO}$ and the metal electrodes, which caused $\mathrm{ZnO}$ to exhibit p-type semiconductor properties. The gas-sensing performance parameters of the abovementioned sensors for reducing gases based on metal oxides and rGO enhanced by the formation of semiconductor interfaces are listed in Table 1.

Similarly, taking a $\mathrm{SnO}_{2}-\mathrm{rGO}$ sensor as an example [55], as displayed in Figure 2 [56], $\mathrm{SnO}_{2}$ and rGO formed $\mathrm{p}-\mathrm{n}$ heterojunctions during the recombination process. The Fermi level of $\mathrm{SnO}_{2}$ is higher than that of $\mathrm{rGO}$ since the work function of $\mathrm{SnO}_{2}(4.55 \mathrm{eV})$ is lower than that of $\mathrm{rGO}(4.75 \mathrm{eV})$. As a result, electrons transfer from $\mathrm{SnO}_{2}$ to the conduction band of $\mathrm{rGO}$, not only leading to the bending of the energy bands but also 


\begin{tabular}{|c|c|c|c|c|c|c|}
\hline target gas & sensor material & synthesis method & conc. (ppm) & response & $\mathrm{T}_{\text {res }} / \mathrm{T}_{\text {recov }}(\mathrm{s})$ & ref. \\
\hline $\mathrm{NH}_{3}$ & $\mathrm{SnO}_{2}$ nanorods-rGO & hydrothermal & 200 & 1.3 & $8 / 13$ & {$[45]$} \\
\hline $\mathrm{NH}_{3}$ & $\mathrm{SnO}_{2}-\mathrm{Pd}-\mathrm{rGO}$ & one-pot route & 5 & $7.6 \%$ & $420 / 3000$ & [53] \\
\hline $\mathrm{NH}_{3}$ & $\mathrm{ZnO}-\mathrm{rGO}$ & precipitation & 10 & 1.2 & 78/188 & {$[46]$} \\
\hline $\mathrm{NH}_{3}$ & ZnO nanowires-rGO & thermal reduction & 50 & $19.2 \%$ & $50 / 250$ & {$[52]$} \\
\hline $\mathrm{NH}_{3}$ & $\mathrm{ZnO}-\mathrm{rGO}$ & hydrothermal & 1 & $24 \%$ & $180 / 150$ & {$[54]$} \\
\hline $\mathrm{CO}$ & CuO-rGO & LBL self-assembly & 1 & $2.56 \%$ & $70 / 160$ & [47] \\
\hline
\end{tabular}

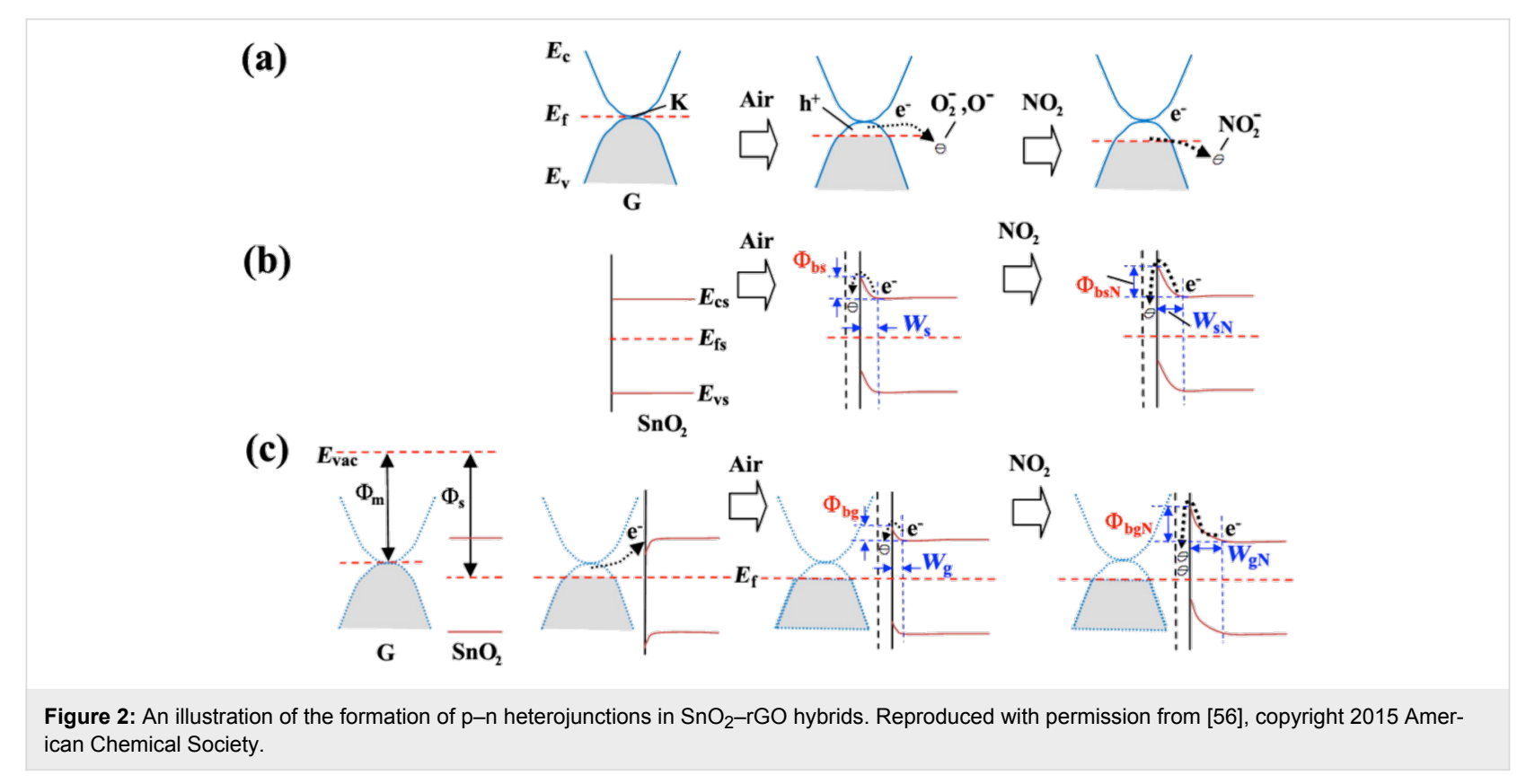

forming potential barriers at the interfaces between $\mathrm{SnO}_{2}$ and rGO. When exposed to air at room temperature, oxygen molecules form $\mathrm{O}_{2}{ }^{-}$by obtaining electrons from p-type $\mathrm{SnO}_{2}-\mathrm{rGO}$ hybrids. Thus, hole accumulation layers and potential barriers are generated at the interfaces of $\mathrm{SnO}_{2}-\mathrm{rGO}$ hybrids. There are wider hole accumulation layers and higher potential barriers in $\mathrm{SnO}_{2}-\mathrm{rGO}$ than in pristine $\mathrm{SnO}_{2}$ owing to the existence of the immanent potential barrier and the imprisoned electrons in $\mathrm{rGO}$. When exposed to an oxidizing gas $\left(\mathrm{NO}_{2}\right)$, which has a high electron affinity, the electrons are continuously captured from $\mathrm{SnO}_{2}-\mathrm{rGO}$ hybrids, leading to wider hole accumulation layers and increased potential barriers. Consequently, the resistance of composite sensor decreased sharply, leading to high sensitivity and rapid response time. The reaction equations are as follows:

$$
\begin{gathered}
\mathrm{NO}_{2}(\text { gas })+\mathrm{e}^{-} \longrightarrow \mathrm{NO}_{2}^{-} \\
2 \mathrm{NO}_{2}(\text { gas })+\mathrm{O}_{2}^{-}(\text {ads })+\mathrm{e}^{-} \longrightarrow 2 \mathrm{NO}_{3}^{-}(\text {ads }) .
\end{gathered}
$$

In an early work, Liu et al. [57] stated that a $\mathrm{ZnO}$ nanowalls-rGO sensor, which was prepared by growing $\mathrm{ZnO}$ nanowalls on rGO films, reached a response of 9.61 to $50 \mathrm{ppm}$ $\mathrm{NO}_{2}$ and the response/recovery times were only $25 \mathrm{~s} / 15 \mathrm{~s}$ with good stability at room temperature. As a comparison, the response of the $\mathrm{ZnO}$ sensor was 6.2 and the response time was over $150 \mathrm{~s}$ under the same conditions. The pure rGO sensor only showed a response of 1.2 and a recovery time up to $58 \mathrm{~s}$. The effect of humidity on this sensor was also tested. It was found that the sensor was relatively stable to different humidity levels. The authors ascribed the enhanced sensing properties to both the $\mathrm{p}-\mathrm{n}$ heterojunctions and the increased carrier concentrations. Specifically, the addition of rGO increased carrier concentrations and provided conductive pathways, which favored the transfer of electrons. The $\mathrm{CeO}_{2}-\mathrm{rGO}$ sensor reported by Jiang et al. [58] exhibited 8.2-times higher sensitivity and faster response than that of a pure $\mathrm{rGO}$ sensor at room temperature. The $\mathrm{p}-\mathrm{n}$ heterojunctions are responsible for the exceptional $\mathrm{NO}_{2}$ sensing performance of $\mathrm{CeO}_{2}-\mathrm{rGO}$ sensor. Zhang et al. [59] added $\mathrm{GO}$ suspension to a $\mathrm{Fe}\left(\mathrm{NO}_{3}\right)_{3} \cdot 9 \mathrm{H}_{2} \mathrm{O}$ solution, then 
synthesized $\alpha-\mathrm{Fe}_{2} \mathrm{O}_{3}-\mathrm{rGO}$ hybrids via hydrothermal method. During the process of testing, the authors found that the doping amount of graphene significantly affected the sensing properties of the $\alpha-\mathrm{Fe}_{2} \mathrm{O}_{3}-\mathrm{rGO}$ sensor. The $\alpha-\mathrm{Fe}_{2} \mathrm{O}_{3}-\mathrm{rGO}$ sensor with the optimal doping amount of $12.2 \%$ showed the highest sensitivity and rapid response time to $\mathrm{NO}_{2}$ at room temperature. In addition, the sensor exhibited excellent selectivity to $\mathrm{NO}_{2}$ because other interference gases required high operating temperatures to react with the surface of this sensor. As a comparison, the pure $\alpha-\mathrm{Fe}_{2} \mathrm{O}_{3}$ sensor does not work at room temperature. The formation of $\mathrm{p}-\mathrm{n}$ heterojunctions was an important factor for the exceptional sensing performance. There were two different depletion layers and potential barriers in the composites due to the heterojunctions, one at the $\alpha-\mathrm{Fe}_{2} \mathrm{O}_{3}$ grain boundaries and another at the interfaces of $\alpha-\mathrm{Fe}_{2} \mathrm{O}_{3}$ and rGO. It appeared clear that $\mathrm{O}_{2}$ adsorption on the $\alpha-\mathrm{Fe}_{2} \mathrm{O}_{3}$ grain boundaries modified the width of the $\alpha-\mathrm{Fe}_{2} \mathrm{O}_{3}$ depletion layer, which conversely altered the width of depletion layer at the $\alpha-\mathrm{Fe}_{2} \mathrm{O}_{3}$ and $\mathrm{rGO}$ interfaces leading to higher sensitivity. In addition, the periodic exposure of the $\alpha-\mathrm{Fe}_{2} \mathrm{O}_{3}-\mathrm{rGO}$ sensor to $0.1 \mathrm{ppm} \mathrm{NO}_{2}$ indicated that the process of response was repeatable. However, a drift of the baseline was easily noted, which usually appears in room-temperature sensors, and further optimization is needed to control the drift. In another work, $\mathrm{p}-\mathrm{p}$ junctions were accounted for the outstanding sensitivity to $\mathrm{NO}_{2}$ of $\mathrm{Co}_{3} \mathrm{O}_{4}-\mathrm{rGO}$ sensors at room temperature [60].

Liu et al. [61] prepared sulfonated reduced graphene oxide (S-rGO) via adding a solution of diazonium salt into a dispersion of partially reduced $\mathrm{GO}$, then $\mathrm{SnO}_{2}$ nanoparticles were grown on S-rGO sheets to prepare $\mathrm{SnO}_{2}-\mathrm{S}-\mathrm{rGO}$ hybrids. The $\mathrm{SnO}_{2}-\mathrm{S}-\mathrm{rGO}$ sensor exhibited exceptional sensitivity to $\mathrm{NO}_{2}$ with a detection limit of $450 \mathrm{ppb}$ at room temperature. The sensor also showed good repeatability and was not affected by water molecules. In contrast, a sensor based on S-rGO showed high sensitivity to $\mathrm{NO}_{2}$, but its response/recovery times were long (more than a few minutes). A gas sensor based on $\mathrm{SnO}_{2}-\mathrm{rGO}$ [62] also exhibited excellent response to $\mathrm{NO}_{2}$ in their previous study, but it could only work at $50-55{ }^{\circ} \mathrm{C}$. The authors ascribed the better sensing performance of the $\mathrm{SnO}_{2}-\mathrm{S}-\mathrm{rGO}$ sensor to the following factors: The addition of sulfonic acid enhances the dispersibility of rGO. At same time, the conductivity of S-rGO is better than that of rGO. Most importantly, the $\mathrm{p}-\mathrm{n}$ heterojunctions between $\mathrm{S}-\mathrm{rGO}$ and $\mathrm{SnO}_{2}$ lead to the good sensing properties. Because noble metals offer exceptional catalytic activity, the same group [55] developed $\mathrm{Ag}-\mathrm{SnO}_{2}-\mathrm{rGO}$ ternary hybrids by reducing $\mathrm{AgNO}_{3}$ on the dispersion of $\mathrm{SnO}_{2}-\mathrm{rGO}$, and the sensing properties were tested at room temperature. The authors demonstrated that the response and recovery of this sensor were much faster than that of $\mathrm{SnO}_{2}-\mathrm{rGO}$ sensor, which could only work at $50-55^{\circ} \mathrm{C}$. The doping of Ag nanoparticles not only improved the electron transfer rate of the sensor, but also increased the number of active sites on the surface of the sensor. Moreover, the introduction of Ag nanoparticles reduced the Schottky barrier of the ternary composites so that those electrons with lower energy were able to cross the energy barrier at room temperature. Thus the sensor can work near room temperature. The most important reason for the excellent $\mathrm{NO}_{2}$ sensing performance of the ternary composite sensor was still the $\mathrm{p}-\mathrm{n}$ heterojunctions. The gas-sensing performance parameters of the abovementioned $\mathrm{NO}_{2}$ sensors based on metal oxides and rGO enhanced by the formation of semiconductor interfaces are listed in Table 2.

\section{Enhancement by improved morphology and structure}

By changing morphology and structure of the sensor materials, one can obtain large specific surface area, more conductive pathways and more active sites, which significantly improve sensing performance of the sensor. As shown in Figure 3 [56], $\mathrm{SnO}_{2}$ nanoparticles prevent graphene from agglomerating, which in turn leads to a high specific surface area. Graphene enhances the conductivity of the composite materials, enabling the composite sensors to achieve a high response at low operating temperatures. Moreover, the introduction of graphene

\begin{tabular}{|c|c|c|c|c|c|}
\hline sensor material & synthesis method & conc. $(p p m)$ & response & $\mathrm{T}_{\mathrm{res}} / \mathrm{T}_{\text {recov }}(\mathrm{s})$ & ref. \\
\hline $\mathrm{Ag}-\mathrm{rGO}-\mathrm{SnO}_{2}$ & hydrothermal & 5 & 2.17 & $49 / 339$ & {$[55]$} \\
\hline $\mathrm{ZnO}$ nanowalls-rGO & soft solution & 50 & 9.61 & $25 / 15$ & {$[57]$} \\
\hline $\mathrm{CeO}_{2}-\mathrm{rGO}$ & spray & 10 & $20.5 \%$ & $92 /-$ & {$[58]$} \\
\hline$\alpha-\mathrm{Fe}_{2} \mathrm{O}_{3}-\mathrm{rGO}$ & hydrothermal & 5 & 8.2 & $126 / 2400$ & [59] \\
\hline $\mathrm{Co}_{3} \mathrm{O}_{4}-\mathrm{rGO}$ & hydrothermal & 5 & $26.8 \%$ & $90 / 2400$ & {$[60]$} \\
\hline $\mathrm{SnO}_{2}-\mathrm{S}-\mathrm{rGO}$ & hydrothermal & 5 & 12.03 & $40 / 357$ & [61] \\
\hline $\mathrm{ZnO}-\mathrm{rGO}$ & solvothermal & 5 & $25.6 \%$ & $165 / 499$ & [63] \\
\hline $\mathrm{WO}_{3}-\mathrm{Fe}-\mathrm{rGO}$ & precipitation & 3 & $5.9 \%$ & $1500 / 7200$ & [64] \\
\hline flower-like $\mathrm{In}_{2} \mathrm{O}_{3}-\mathrm{rGO}$ & hydrothermal & 1 & 1098 & $-1-$ & [65] \\
\hline
\end{tabular}




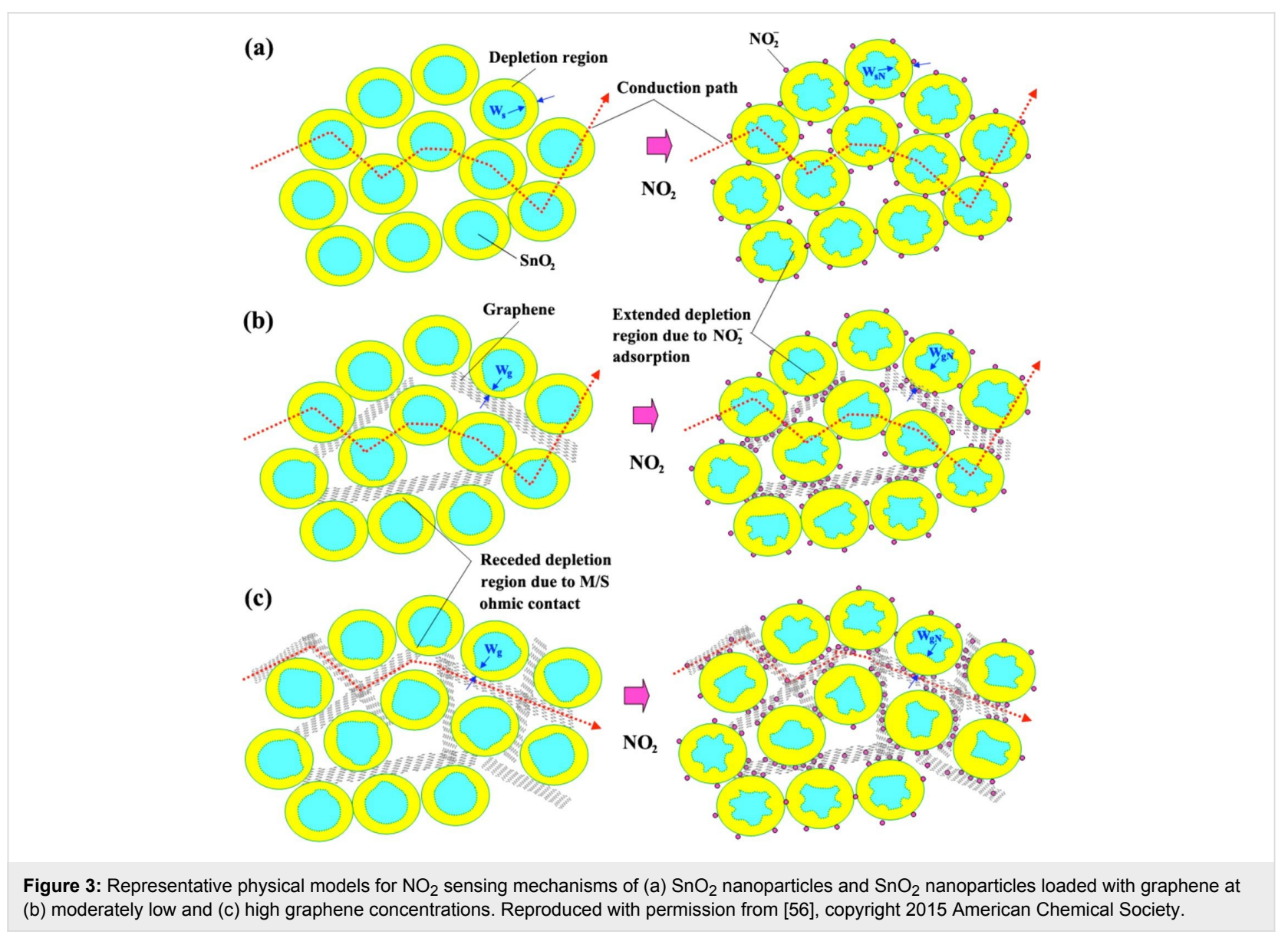

provides more adsorption sites at the surface of the composite so that the response can be significantly improved.

$\mathrm{ZnO}$ is widely used as a typical wide-bandgap $(3.37 \mathrm{eV})$ metaloxide gas sensor material. However, the problem with $\mathrm{ZnO}$ gas sensors is their poor selectivity [66]. Li et al. [67] synthesized urchin-like $\mathrm{ZnO}$ nanorods-graphene via a facile solvothermal method. The urchin-like morphology of the samples provided a large specific surface area. The response of the sensor was $17.4 \%$ to $100 \mathrm{ppm} \mathrm{NO}_{2}$ at room temperature, while the pure rGO sensor only exhibited $7.7 \%$ response under the same conditions. Apart from the conductive 3D network channels provided by rGO, the large specific surface area of the composite sensor also contributed to the high response. Liu et al. [68] developed a 3D $\mathrm{ZnO}-\mathrm{rGO}$ aerogel by heating $\left(200^{\circ} \mathrm{C}\right.$ for $\left.10 \mathrm{~h}\right)$ a mixture of $\mathrm{ZnCl}_{2}$, GO, sodium acetate and sodium citrate in an autoclave. Different from other drying processes, the hybrids were obtained through freeze-drying to keep the 3D structure. $\mathrm{ZnO}$ nanoparticles were well wrapped in graphene sheets, while the graphene sheets were well dispersed in the hybrids. The ZnO-rGO sensor exhibited $8 \%$ response to $50 \mathrm{ppm} \mathrm{NO}_{2}$ with rather rapid response/recovery times (132 s/164 s) while the pure rGO sensor showed a response of $6.4 \%$ with longer response/recovery times ( $149 \mathrm{~s} / 243 \mathrm{~s})$ at room temperature. The sensor showed exceptional selectivity to $\mathrm{NO}_{2}$. Other gases, such as $\mathrm{C}_{3} \mathrm{H}_{6} \mathrm{O}, \mathrm{CH}_{3}\left(\mathrm{CH}_{2}\right)_{3} \mathrm{OH}, \mathrm{CH}_{3} \mathrm{OH}$ and $\mathrm{H}_{2}$, were not able to react with the oxygen ions that adsorbed on the surface of this composite sensor at low operating temperatures. $\mathrm{NO}_{2}$ is a strongly electron-withdrawing molecule that enhanced the electron-withdrawing ability of oxygen functional groups through its electron-deficient $\mathrm{N}$ atom interacting with active sites on rGO. In addition, the authors did an interesting comparative experiment with the $\mathrm{ZnO}-\mathrm{rGO}$ sensor, a pure $\mathrm{rGO}$ sensor and a sensor fabricated by physically mixing $\mathrm{ZnO}$ and graphene dispersions. The last sensor exhibited the worst gas-sensing performance to $\mathrm{NO}_{2}$ due to the agglomeration of graphene sheets and $\mathrm{ZnO}$ particles. Similarly, this group [69] demonstrated that a room-temperature sensor composed of a 3D graphene aerogel and $\mathrm{SnO}_{2}$ nanoparticles, synthesized via the method mentioned above, exhibited a higher response to $\mathrm{NO}_{2}$ and faster response/ recovery times than a $2 \mathrm{D}_{\mathrm{SnO}_{2}}$-graphene sensor, fabricated by the same method without freeze-drying process.

Titanium dioxide $\left(\mathrm{TiO}_{2}\right)$, as a wide-bandgap semiconductor, has been widely used as photocatalyst, and in solar cells and gas sensors [70-72]. In general, its operating temperature is over 
$200{ }^{\circ} \mathrm{C}$, so scholars try to prepare composites with graphene to reduce its operating temperature. However, the stability of this type of composite sensors is a problem. Recently Li et al. [73] reported an ultrafast and sensitive $\mathrm{NH}_{3}$ sensor using rGO decorated with $\mathrm{TiO}_{2}$ nanocrystals. There were two different morphologies in these sensing materials: rGO either laid on the surface of $\mathrm{TiO}_{2}$ nanoparticles, partly wrapping them, or made "bridges" at the interface between two nanoparticles. Due to the "bridges" existing between $\mathrm{TiO}_{2}$ nanoparticles, the initial resistance of $\mathrm{TiO}_{2}-\mathrm{rGO}$ sensor was greatly reduced, indicating that the sensor was able to work at room temperature. The partly "wrapping" microstructure enhanced the number of adsorption sites. Moreover, the $\mathrm{TiO}_{2}-\mathrm{rGO}$ sensor showed a better selectivity to $\mathrm{NH}_{3}$ than the pure rGO sensor owing to the acidic surface of $\mathrm{TiO}_{2}$ preferentially adsorbing primarily $\mathrm{NH}_{3}$. Ye et al. [74] stated that a $\mathrm{TiO}_{2}-\mathrm{rGO}$ sensor, fabricated via depositing $\mathrm{GO}$ and $\mathrm{TiO}_{2}$ nanoparticles on IDEs and then heating them for reduction, showed a 1.5 -times higher response than a $\mathrm{rGO}$ sensor at room temperature. In contrast, a pure $\mathrm{TiO}_{2}$ sensor did not respond to $\mathrm{NH}_{3}$ at room temperature, which proved that the introduction of graphene reduced the operating temperature of the $\mathrm{TiO}_{2}$ sensor. The same group [75] reported that a $\mathrm{NH}_{3}$ room-temperature sensor based on $\mathrm{TiO}_{2}-\mathrm{rGO}$ hybrids, synthesized by a hydrothermal method, exhibited a two-times higher response and a much shorter response time than the $\mathrm{TiO}_{2}-\mathrm{rGO}$ sensor fabricated by direct deposition as mentioned above. Apart from the porous and undulating graphene sheets due to the introduction of $\mathrm{TiO}_{2}$ nanoparticles, the mellow and regular $\mathrm{TiO}_{2}$ nanoparticles also contributed to the improvement of the gas-sensing performance. However, the stability was poor because the composite sensor was sensitive to water molecules. Further optimization is needed to control the influence of humidity on the sensors.

$\mathrm{SnO}_{2}$, a semiconductor with a bandgap of $3.62 \mathrm{eV}$, has an exceptional response to toxic industrial gases. However, a pure $\mathrm{SnO}_{2}$ sensor has low sensitivity at low concentrations of gases $[76,77]$, so the combination of graphene and $\mathrm{SnO}_{2}$ has attracted widespread attention. In a pioneering work, Lin et al. [78] demonstrated that $\mathrm{SnO}_{2}$-graphene (GN) hybrids fabricated via hydrothermal synthesis using $\mathrm{GO}$ and $\mathrm{SnCl}_{2}$ as precursors exhibited a 3D nanostructure with high specific surface area $\left(94.9 \mathrm{~m}^{2} / \mathrm{g}\right)$. During the hydrothermal process, GO served as a template to promote the preferential growth of $\mathrm{SnO}_{2}$ nanoparticles and prevented $\mathrm{SnO}_{2}$ nanoparticles from agglomeration. The response of the composite sensor to $\mathrm{NH}_{3}$ at $10 \mathrm{ppm}$ was $5.09 \%$ and the response/recovery time was less than $1 \mathrm{~min}$ at room temperature, whereas the sensor based on $\mathrm{SnO}_{2}$ did not respond to $\mathrm{NH}_{3}$ and the sensor based on GN showed a response of only $2.7 \%$ at room temperature. The authors claimed that the introduction of GN not only increased the specific surface area, but also improved the conductivity of the sensor at room temperature. Bo et al. [79] grew vertical graphene (VG) on the surface of Pt IDEs, then used chronoamperometry to deposit $\mathrm{SnO}_{2}$ nanoparticles on the VG networks. The $\mathrm{SnO}_{2}-\mathrm{VG}$ room-temperature sensor was capable of detecting as low as $20 \mathrm{ppb}$ of formaldehyde and showed a response of $4.6 \%$ to $5 \mathrm{ppm}$ formaldehyde, which was three-times higher than that of the graphene sensor. Compared with normal graphene sheets, the specific surface area of vertical graphene sheets is extremely increased. The $\mathrm{SnO}_{2}$ nanoparticles on the VG sheets with the 3D structure provided numerous adsorption sites for target gas molecules.

Apart from the abovementioned common MOS, some other MOS also have exceptional sensing properties after mixing with graphene. Yang et al. [80] added a GO suspension, prepared via a modified Hummers method, to a solution of $\operatorname{In}\left(\mathrm{NO}_{3}\right)_{3}$ to develop $\mathrm{In}_{2} \mathrm{O}_{3}$-rGO hybrids through a facile one-step microwave-assisted hydrothermal method. The response of the $\mathrm{In}_{2} \mathrm{O}_{3}-\mathrm{rGO}$ sensor to $5 \mathrm{ppm} \mathrm{NO} \mathrm{NO}_{2}$ was $37.81 \%$ with excellent stability and selectivity at room temperature. It should be noted that graphene improved the conductivity of the sensing materials, while the addition of $\operatorname{In}_{2} \mathrm{O}_{3}$ nanocubes prevented rGO sheets from re-accumulation, as shown in Figure 4, leading to an increased specific surface areas and a higher number of active sites. Meng and co-workers [81] published an inspiring

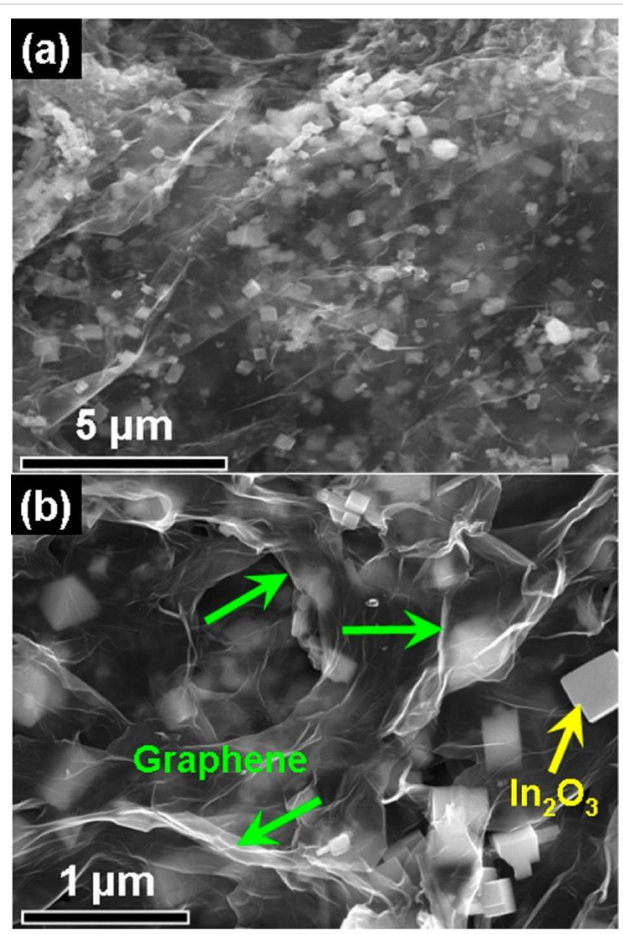

Figure 4: SEM images of the $\ln _{2} \mathrm{O}_{3}$ cubes-rGO composites at different magnification. Reproduced with permission from [80], copyright 2014 American Chemical Society. 
study, where they develop a microwave-assisted hydrothermal technique to grow $\mathrm{CuO}$ rods in $\mathrm{GO}$ suspension using cetyltrimethylammonium bromide (CTAB) as a soft template. The $\mathrm{Cu}_{2} \mathrm{O}$ nanorods- $\mathrm{rGO}$ hybrids obtained after annealing showed a porous structure with a high surface area to volume ratio. The porous structure promoted the diffusion of gases, improving the reaction of gases with oxygen species on the surface of the hybrid material. The $\mathrm{Cu}_{2} \mathrm{O}-\mathrm{rGO}$ composites exhibited exceptional catalytic activity and acted as high-efficiency catalysts for the reduction of oxygen molecules, leading to an excellent response. This room-temperature sensor exhibited a linear response to the concentration of $\mathrm{NH}_{3}$ with rapid response/ recovery times. The gas-sensing performance parameters of the abovementioned graphene/metal-oxide gas sensors enhanced by improved morphology and structure are listed in Table 3.

\section{Enhancement by a synergetic coupling effect between graphene and metal oxides}

In the past years, some scholars have found that excellent sensing properties can also be achieved when MOS are directly mixed with pristine graphene. The formation of heterojunctions is improper to explain this phenomenon since pristine graphene is a conducting material. Also, the morphology and structure of the composite sensor have not been altered through the introduction of graphene. Another strengthening mechanism, namely a synergetic coupling effect between graphene and metal oxides, is proposed. In detail, the enhanced sensing performance is accounted for by chemical bonds between graphene and metal oxides. Many XPS studies have claimed that there indeed exist chemical bonds between metal oxides and graphene.
$\mathrm{WO}_{3}$, a transition-metal oxide semiconductor is widely used as a gas sensor because of its small bandgap $(2.585 \mathrm{eV})$ and its physical and chemical stability $[88,89]$. In an early work, Jie et al. [90] reported that a $\mathrm{NO}_{2}$ sensor based on $\mathrm{WO}_{3}$ nanospheres wrapped in graphene sheets, prepared by a simple sol-gel technique, showed a linear response to low concentrations of $\mathrm{NO}_{2}$, while the pure $\mathrm{WO}_{3}$ and graphene sensors did not respond to $\mathrm{NO}_{2}$ at room temperature. The authors claimed that the reason for room-temperature sensing of the composite sensor was the effective charge transfer between graphene and $\mathrm{WO}_{3}$ nanospheres by chemical bonds. The research group confirmed that there existed $\mathrm{C}-\mathrm{O}-\mathrm{W}$ chemical bonds between $\mathrm{WO}_{3}$ and graphene by Raman and XPS measurements. The proposed sensing mechanism is shown in Figure 5. When exposed to oxygen or $\mathrm{NO}_{2}$ molecules, the gas molecules adsorbed on $\mathrm{WO}_{3}$ nanospheres cause the energy band to bend upward via obtaining electrons from $\mathrm{WO}_{3}$ and move the Fermi level of $\mathrm{WO}_{3}$ from the conduction band to the valence band. The reactions mentioned above shift the work function of $\mathrm{WO}_{3}$ [91] to be adjacent to graphene, leading to the electrons moving easily at the interfaces of $\mathrm{WO}_{3}$ and graphene. Because of the continuous loss of electrons of $\mathrm{WO}_{3}$, electrons are transferred from the graphene sheets to $\mathrm{WO}_{3}$ through chemical bonds to maintain the adsorption. The chemical bonds are considered as electrons bridges during the response, which improved the sensing performance of the graphene- $\mathrm{WO}_{3}$ sensor. In addition, the excellent conductivity of graphene may also enhance the response because graphene offers conductive pathways that enhanced the efficiency of charge-carrier transfer in the composites. Zhang et al. [60] fabricated a $\mathrm{Co}_{3} \mathrm{O}_{4}-$ graphene gas sensor through a traditional hydrothermal method. The XPS results certified that

\begin{tabular}{|c|c|c|c|c|c|c|}
\hline target gas & sensor material & synthesis method & conc. $(p p m)$ & response & $\mathrm{T}_{\text {res }} / \mathrm{T}_{\text {recov }}(\mathrm{s})$ & ref. \\
\hline $\mathrm{NO}_{2}$ & $\mathrm{ZnO}-\mathrm{rGO}$ & solvothermal & 100 & $17.4 \%$ & $780 / 1980$ & {$[67]$} \\
\hline $\mathrm{NO}_{2}$ & $\mathrm{ZnO}-\mathrm{rGO}$ aerogel & solvothermal & 50 & $8 \%$ & $132 / 164$ & [68] \\
\hline $\mathrm{HCHO}$ & $\mathrm{ZnO}-\mathrm{rGO}$ & hydrothermal & 2 & $2 \%$ & $60 /-$ & {$[82]$} \\
\hline $\mathrm{HCHO}$ & $\mathrm{ZnO}-\mathrm{rGO}$ & CVD & 9 & $52 \%$ & $36 /-$ & [83] \\
\hline $\mathrm{NH}_{3}$ & $\mathrm{TiO}_{2}-\mathrm{rGO}$ & hydrothermal & 30 & $3.3 \%$ & $-1-$ & [73] \\
\hline $\mathrm{NH}_{3}$ & $\mathrm{TiO}_{2}-\mathrm{rGO}$ & precipitation & 10 & 0.62 & $55 / 200$ & {$[74]$} \\
\hline $\mathrm{NH}_{3}$ & $\mathrm{TiO}_{2}-\mathrm{rGO}$ & hydrothermal & 10 & 1.7 & $114 / 304$ & [75] \\
\hline $\mathrm{NO}_{2}$ & $\mathrm{SnO}_{2}-\mathrm{rGO}$ aerogel & solvothermal & 50 & $6 \%$ & $190 / 224$ & [69] \\
\hline $\mathrm{NH}_{3}$ & $\mathrm{SnO}_{2}-\mathrm{GN}$ & hydrothermal & 10 & $5.9 \%$ & $<60 /<60$ & [78] \\
\hline $\mathrm{HCHO}$ & $\mathrm{SnO}_{2}-\mathrm{VG}$ & CVD & 5 & $4.6 \%$ & $46 / 95$ & [79] \\
\hline $\mathrm{NO}_{2}$ & $\mathrm{In}_{2} \mathrm{O}_{3}-\mathrm{rGO}$ & hydrothermal & 5 & $37.81 \%$ & $-1-$ & [80] \\
\hline $\mathrm{NO}_{2}$ & $\mathrm{In}_{2} \mathrm{O}_{3}-\mathrm{rGO}$ & hydrothermal & 30 & 8.25 & $240 / 1440$ & {$[85]$} \\
\hline $\mathrm{NH}_{3}$ & $\mathrm{Cu}_{2} \mathrm{O}-\mathrm{rGO}$ & hydrothermal & 200 & 2.04 & $28 / 206$ & {$[81]$} \\
\hline $\mathrm{NO}_{2}$ & $\mathrm{Cu}_{x} \mathrm{O}$-graphene & vacuum-assisted reflux & 0.097 & $27.1 \%$ & $58.7 /-$ & {$[87]$} \\
\hline $\mathrm{NO}_{2}$ & $\mathrm{WO}_{3}-\mathrm{rGO}$ & one-pot polyol & 5 & $769 \%$ & $540 / 1080$ & [84] \\
\hline $\mathrm{NO}_{2}$ & $\alpha-\mathrm{Fe}_{2} \mathrm{O}_{3}-\mathrm{rGO}$ & hydrothermal & 90 & $150.63 \%$ & $-/ 1648$ & {$[86]$} \\
\hline
\end{tabular}




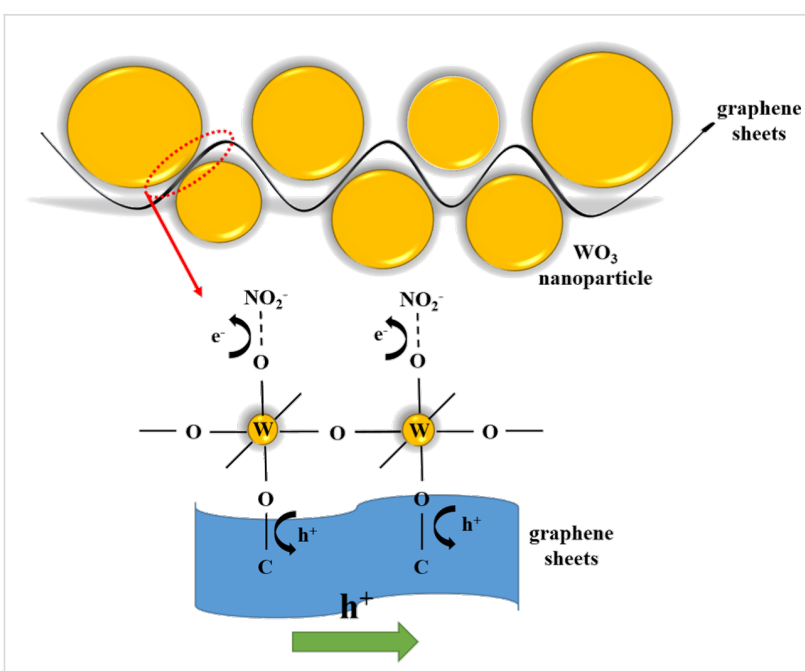

Figure 5: Proposed $\mathrm{NO}_{2}$-sensing mechanism of $\mathrm{GR}-\mathrm{WO}_{3}$ composites at room temperature and electron transfer between $\mathrm{WO}_{3}$ nanospheres and graphene sheets.

$\mathrm{Co}-\mathrm{O}-\mathrm{C}$ bonds were formed at the interfaces of $\mathrm{Co}_{3} \mathrm{O}_{4}$ and graphene. The Co cations in $\mathrm{Co}_{3} \mathrm{O}_{4}$ were strongly attracted by the oxygen anions in the oxygen functional groups of the graphene. Consequently, the centers of $\mathrm{Co}^{3+}$ and $\mathrm{Co}^{2+}$ served as additional active adsorption sites for $\mathrm{NO}_{2}$. At the same time, the electrons transferred from graphene to $\mathrm{Co}_{3} \mathrm{O}_{4}$ through the $\mathrm{Co}-\mathrm{O}-\mathrm{C}$ bonds lead to an additional increase of the width of hole accumulation layers, leading to a high sensitivity at room temperature. In another work, Feng et al. [92] developed composite nanofibers of rGO-coated $\mathrm{Co}_{3} \mathrm{O}_{4}$ nanocrystals by using electrospinning. The $\mathrm{Co}_{3} \mathrm{O}_{4}-\mathrm{rGO}$ room-temperature sensor showed excellent sensitivity to low concentrations of $\mathrm{NH}_{3}$, an ultrafast response time of only $4 \mathrm{~s}$ with exceptional selectivity to $\mathrm{NH}_{3}$. The authors claimed that the introduction of $\mathrm{rGO}$ exhibiting a strong attraction to $\mathrm{NH}_{3}$ played a crucial role in improving the sensitivity and selectivity. However, the most important factor was that the chemical bonds $(\mathrm{C}-\mathrm{O}-\mathrm{Co})$ formed between $\mathrm{rGO}$ and $\mathrm{Co}_{3} \mathrm{O}_{4}$, which facilitated the electrons transfer at the interfaces of $\mathrm{rGO}$ and $\mathrm{Co}_{3} \mathrm{O}_{4}$.

Kumar and co-workers [93] fabricated $\mathrm{SnO}-$ graphene gas sensors through heating mixtures of $\mathrm{SnCl}_{2}$ and graphene. The response of the $\mathrm{SnO}-$ graphene sensor to $50 \mathrm{ppm} \mathrm{NH}_{3}$ reached $21 \%$ with fast response/recovery times of only $15 \mathrm{~s} / 30 \mathrm{~s}$ at room temperature. The most encouraging result was that the sensor could maintain its excellent response for more than one year. The authors demonstrated that the formation of $\mathrm{C}-\mathrm{O}-\mathrm{Sn}$ chemical bonds, confirmed by XPS results, was responsible for the superior performance of the $\mathrm{SnO}$-graphene sensor. Zhang et al. [94] fabricated a room-temperature $\mathrm{NiO}$-graphene sensor that exhibited a better sensitivity to $\mathrm{NO}_{2}$ than a pure $\mathrm{NiO}$ sensor. The authors also ascribed the enhanced sensor sensitivity to the $\mathrm{Ni}-\mathrm{O}-\mathrm{C}$ bonds formed at the interfaces of $\mathrm{NiO}$ nanoparticles and graphene sheets. The $\mathrm{NO}_{2}$ molecules capture electrons from the surface of $\mathrm{NiO}$ nanoparticles when the sensor is exposed to $\mathrm{NO}_{2}$. More and more electrons are transferred from graphene to $\mathrm{NiO}$ by $\mathrm{Ni}-\mathrm{O}-\mathrm{C}$ bonds because of the lower Fermi level of $\mathrm{NiO}$, increasing the sensitivity and response rate of the NiO-graphene sensor. However, the sensitivity of the $\mathrm{NiO}$-graphene sensor was not as good as that of the pure $\mathrm{NiO}$ sensor at low concentrations of $\mathrm{NO}_{2}(0.25-1 \mathrm{ppm})$. In order to enhance the sensitivity of this sensor, the authors [95] added n-type semiconductor $\mathrm{SnO}_{2}$ to the $\mathrm{NiO}$-graphene hybrids (p-type) to form $\mathrm{p}-\mathrm{n}$ heterojunctions and found that the sensitivity of the $\mathrm{SnO}_{2}-\mathrm{NiO}$-graphene sensor was about 10-times that of the NiO-graphene sensor. The authors claimed that the low adsorption energy of $\mathrm{NO}_{2}$ on the surface of $\mathrm{SnO}_{2}$ and the formation of $\mathrm{p}-\mathrm{n}$ heterojunctions contributed to the exceptional sensitivity. The gas-sensing performance parameters of the abovementioned metal oxide-graphene gas sensors enhanced by a synergetic coupling effect are listed in Table 4.

Table 4: Gas-sensing performance of graphene/metal-oxide sensors at room temperature.

\begin{tabular}{|c|c|c|c|c|c|c|}
\hline target gas & sensor material & synthesis method & conc. (ppm) & response & $\mathrm{T}_{\mathrm{res}} / \mathrm{T}_{\text {recov }}(\mathrm{s})$ & ref. \\
\hline $\mathrm{NO}_{2}$ & $\mathrm{Co}_{3} \mathrm{O}_{4}-\mathrm{rGO}$ & hydrothermal & 5 & $26.8 \%$ & $90 / 2400$ & {$[60]$} \\
\hline $\mathrm{NO}_{2}$ & $\mathrm{Co}_{3} \mathrm{O}_{4}-\mathrm{rGO}$ & hydrothermal & 60 & $82 \%$ & $300 /-$ & [101] \\
\hline $\mathrm{NH}_{3}$ & $\mathrm{Co}_{3} \mathrm{O}_{4}-\mathrm{rGO}$ & electrospinning & 5 & $53.6 \%$ & $4 / 300$ & [92] \\
\hline $\mathrm{NO}_{2}$ & $\mathrm{NiO}-\mathrm{rGO}$ & solvothermal & 60 & 6.2 & $-1-$ & {$[94]$} \\
\hline $\mathrm{NH}_{3}$ & SnO-graphene & CVD & 50 & $21 \%$ & $15 / 30$ & [93] \\
\hline $\mathrm{NO}_{2}$ & $\mathrm{SnO}_{2}-\mathrm{NiO}-\mathrm{rGO}$ & hydrothermal & 60 & 62.27 & $220 / 835$ & [95] \\
\hline $\mathrm{NO}_{2}$ & $\mathrm{SnO}_{2}$-graphene & sol-gel & 20 & $9.6 \%$ & $60 / 300$ & [100] \\
\hline $\mathrm{NH}_{3}$ & $\mathrm{TiO}_{2}-\mathrm{Pd}-\mathrm{rGO}$ & one-pot polyol & 10 & $14.9 \%$ & $184 / 81$ & {$[96]$} \\
\hline $\mathrm{HCHO}$ & $\mathrm{TiO}_{2}-\mathrm{rGO}$ & thermal reduction & 0.5 & 0.4 & $70 / 126$ & {$[97]$} \\
\hline $\mathrm{NH}_{3}$ & $\mathrm{ZnO}-\mathrm{rGO}$ & precipitation & 0.5 & 5.6 & $6 / 36$ & [98] \\
\hline $\mathrm{HCHO}$ & $\mathrm{ZnO}-\mathrm{rGO}$ & solution-processed & 25 & 0.43 & $30 / 40$ & [99] \\
\hline $\mathrm{NO}_{2}$ & $\mathrm{WO}_{3}-\mathrm{GR}$ & sol-gel & 7 & $11.6 \%$ & $-1-$ & [90] \\
\hline
\end{tabular}




\section{Summary and Outlook}

In this review article, the progress of room-temperature graphene/metal-oxide gas sensors has been summarized. The introduction of graphene or its derivatives greatly improves the sensitivity and reduces the operating temperature of MOS gas sensors. The advances in the field of graphene/metal-oxide gas sensors over the past few years have greatly broadened the research directions of gas sensors. However, the achievements reported in this article are still in the stage of basic research and require a lot of effort to put these researches into practical use. The main bottleneck is that the gas sensors are susceptible to environmental humidity [45-47,52,73-75,83,87,96]. In a recent study, a humidity sensor based on $\mathrm{SnO}_{2}-\mathrm{rGO}$ fabricated by Zhang et al. [102] showed a high sensitivity over the full range of humidity at room temperature, which demonstrated that these types of composite sensors are moisture-sensitive by nature. Although several researches demonstrate that the properties of these sensors are capable to be maintained for more than half a year, such stability has been only obtained in laboratory environments, indicating that it is difficult to have such long-term stability in the real environment. Another problem is to explore the ability to detect nonpolar and large molecules, such as volatile organic compounds (VOCs) which are extremely harmful to human health and the environment. The interaction of these molecules with graphene/metal-oxide sensors is different from that of the polar molecules, and graphene showed low surface affinity to these molecules, which makes detection difficult.

A small number of these composite sensors seem to exhibit the phenomenon of resistance-baseline drift, which is due to the formation of chemical bonds during the adsorption of gas molecules at the material surface, resulting in slow or even impossible recovery. Some researchers have stated that the recovery time can be reduced by heating or irradiating with UV light. Unfortunately, the measures will damage the structure of rGO films and increase the cost. Another point we have to mention is that the sensors based on metal oxides and graphene exhibit complicated sensing mechanisms owing to the additional reactions between gas molecules and various sensing materials.

Future works should focus on the following aspects: The most important thing is to simulate the influence of humidity on the sensor performance in a real environment and study the mechanism of humidity influence. A hydrophobic coating can be applied to the surface of the sensor to reduce the effects of humidity. Regarding the synthesis, it is important to quantify and control the effect of hydrothermal or solvothermal parameters on the micromorphology of hybrids. An important way to enhance the selectivity of composite sensors is mixing or doping with other phases (noble metals or conducting polymers). Similarly, the recovery time can be reduced by sur- face functionalization of graphene/metal-oxide hybrids with specific functional molecules such as boron or nitrogen. In addition, more effort should be dedicated to the detection of more environmental gases, especially VOCs. Last but not least, the influence of baseline drift in resistance can be eliminated by defining a new method, which calculates the response values by using the resistance value after each response cycle.

\section{Acknowledgements}

This work is supported by the Natural Science Foundation of China under Grant No. 51402255 and 51872254, Six Talent Peaks Project in Jiangsu Province under Grant No. JXQC-031, Yangzhou Science Fund for Distinguished Young Scholars under Grant No. YZ2017096 and Marine Science and Technology Project of Jiangsu Province under Grant No. HY2017-10.

\section{ORCID ${ }^{\circledR}$ iDs}

Chao Zhang - https://orcid.org/0000-0003-2346-6770

\section{References}

1. Novoselov, K. S.; Geim, A. K.; Morozov, S. V.; Jiang, D.; Katsnelson, M. L.; Grigorieva, I. V. Science 2004, 306, 666-669. doi:10.1126/science.1102896

2. Schedin, F.; Geim, A. K.; Morozov, S. V.; Hill, E. W.; Blake, P.; Katsnelson, M. I.; Novoselov, K. S. Nat. Mater. 2007, 6, 652-655. doi:10.1038/nmat1967

3. Stankovich, S.; Dikin, D. A.; Piner, R. D.; Kohlhaas, K. A.; Kleinhammes, A.; Jia, Y.; Wu, Y.; Nguyen, S. T.; Ruoff, R. S. Carbon 2007, 45, 1558-1565. doi:10.1016/j.carbon.2007.02.034

4. Huang, X.; Qi, X.; Boey, F.; Zhang, H. Chem. Soc. Rev. 2012, 41, 666-686. doi:10.1039/c1cs15078b

5. Wu, Z.-S.; Ren, W.; Wen, L.; Gao, L.; Zhao, J.; Chen, Z.; Zhou, G.; Li, F.; Cheng, H.-M. ACS Nano 2010, 4, 3187-3194. doi:10.1021/nn100740x

6. Gupta Chatterjee, S.; Chatterjee, S.; Ray, A. K.; Chakraborty, A. K. Sens. Actuators, B 2015, 221, 1170-1181. doi:10.1016/j.snb.2015.07.070

7. Lu, G.; Ocola, L. E.; Chen, J. Nanotechnology 2009, 20, 445502. doi:10.1088/0957-4484/20/44/445502

8. Robinson, J. T.; Perkins, F. K.; Snow, E. S.; Wei, Z.; Sheehan, P. E. Nano Lett. 2008, 8, 3137-3140. doi:10.1021/nl8013007

9. Fan, Y.; Kang, L.; Zhou, W.; Jiang, W.; Wang, L.; Kawasaki, A. Carbon 2015, 81, 83-90. doi:10.1016/j.carbon.2014.09.027

10. Fowler, J. D.; Allen, M. J.; Tung, V. C.; Yang, Y.; Kaner, R. B.; Weiller, B. H. ACS Nano 2009, 3, 301-306. doi:10.1021/nn800593m

11. Choi, Y. R.; Yoon, Y.-G.; Choi, K. S.; Kang, J. H.; Shim, Y.-S.; Kim, Y. H.; Chang, H. J.; Lee, J.-H.; Park, C. R.; Kim, S. Y.; Jang, H. W. Carbon 2015, 91, 178-187. doi:10.1016/j.carbon.2015.04.082

12. Gómez-Navarro, C.; Weitz, R. T.; Bittner, A. M.; Scolari, M.; Mews, A.; Burghard, M.; Kern, K. Nano Lett. 2007, 7, 3499-3503. doi:10.1021/nl072090c

13. Ko, G.; Jung, Y.; Lee, K.-Y.; Lee, K.; Kim, J. J. Cryst. Growth 2011, 326, 208-211. doi:10.1016/j.jcrysgro.2011.01.099

14. Gilje, S.; Han, S.; Wang, M.; Wang, K. L.; Kaner, R. B. Nano Lett. 2007, 7, 3394-3398. doi:10.1021/nl0717715 
15. Moser, J.; Verdaguer, A.; Jiménez, D.; Barreiro, A.; Bachtold, A. Appl. Phys. Lett. 2008, 92, 123507. doi:10.1063/1.2898501

16. Wu, X.; Sprinkle, M.; Li, X.; Ming, F.; Berger, C.; de Heer, W. A. Phys. Rev. Lett. 2008, 101, 026801. doi:10.1103/physrevlett.101.026801

17. Zhang, J.; Zeng, D.; Wang, H.; Qin, Z.; Pang, A.; Xie, C. Mater. Lett. 2017, 204, 27-30. doi:10.1016/j.matlet.2017.06.008

18. Hu, N.; Yang, Z.; Wang, Y.; Zhang, L.; Wang, Y.; Huang, X.; Wei, H.; Wei, L.; Zhang, Y. Nanotechnology 2014, 25, 025502. doi:10.1088/0957-4484/25/2/025502

19. He, Q.; Sudibya, H. G.; Yin, Z.; Wu, S.; Li, H.; Boey, F.; Huang, W.; Chen, P.; Zhang, H. ACS Nano 2010, 4, 3201-3208. doi:10.1021/nn100780v

20. Yavari, F.; Chen, Z.; Thomas, A. V.; Ren, W.; Cheng, H.-M.; Koratkar, N. Sci. Rep. 2011, 1, 166. doi:10.1038/srep00166

21. Urasinska-Wojcik, B.; Vincent, T. A.; Chowdhury, M. F.; Gardner, J. W. Sens. Actuators, B 2017, 239, 1051-1059. doi:10.1016/j.snb.2016.08.080

22. Patil, S. P.; Patil, V. L.; Shendage, S. S.; Harale, N. S.; Vanalakar, S. A.; Kim, J. H.; Patil, P. S. Ceram. Int. 2016, 42, 16160-16168. doi:10.1016/j.ceramint.2016.07.135

23. Geng, X.; You, J.; Wang, J.; Zhang, C. Mater. Chem. Phys. 2017, 191, 114-120. doi:10.1016/j.matchemphys.2017.01.046

24. Xu, T.; Pei, Y.; Liu, Y.; Wu, D.; Shi, Z.; Xu, J.; Tian, Y.; Li, X. J. Alloys Compd. 2017, 725, 253-259. doi:10.1016/j.jallcom.2017.06.105

25. Zhang, D.; Liu, J.; Jiang, C.; Li, P.; Sun, Y. Sens. Actuators, B 2017, 245, 560-567. doi:10.1016/j.snb.2017.01.200

26. Zhang, D.; Liu, J.; Jiang, C.; Liu, A.; Xia, B. Sens. Actuators, B 2017, 240, 55-65. doi:10.1016/j.snb.2016.08.085

27. Zhang, D.; Yin, N.; Xia, B. J. Mater. Sci.: Mater. Electron. 2015, 26, 5937-5945. doi:10.1007/s10854-015-3165-2

28. Sun, Y.; Zhang, D.; Chang, H.; Zhang, Y. J. Mater. Sci.: Mater. Electron. 2017, 28, 1667-1673. doi:10.1007/s10854-016-5710-z

29. Dey, A. Mater. Sci. Eng., B 2018, 229, 206-217. doi:10.1016/j.mseb.2017.12.036

30. Cai, Y.; Fan, H. CrystEngComm 2013, 15, 9148-9153. doi:10.1039/c3ce41374h

31. Patil, P.; Gaikwad, G.; Patil, D. R.; Naik, J. Bull. Mater. Sci. 2016, 39, 655-665. doi:10.1007/s12034-016-1208-9

32. Korotcenkov, G.; Cho, B. K. Prog. Cryst. Growth Charact. Mater. 2012, 58, 167-208. doi:10.1016/j.pcrysgrow.2012.07.001

33. Park, S.; An, S.; Mun, Y.; Lee, C. ACS Appl. Mater. Interfaces 2013, 5, 4285-4292. doi:10.1021/am400500a

34. Zhu, L.; Zeng, W. Sens. Actuators, A 2017, 267, 242-261. doi:10.1016/j.sna.2017.10.021

35. Wang, D.; Zhang, M.; Chen, Z.; Li, H.; Chen, A.; Wang, X.; Yang, J. Sens. Actuators, B 2017, 250, 533-542. doi:10.1016/j.snb.2017.04.164

36. Zou, R.; He, G.; Xu, K.; Liu, Q.; Zhang, Z.; Hu, J. J. Mater. Chem. A 2013, 1, 8445-8452. doi:10.1039/c3ta11490b

37. Guo, D.; Cai, P.; Sun, J.; He, W.; Wu, X.; Zhang, T.; Wang, X.; Zhang, X. Carbon 2016, 99, 571-578. doi:10.1016/j.carbon.2015.12.074

38. Chu, X.; Hu, T.; Gao, F.; Dong, Y.; Sun, W.; Bai, L. Mater. Sci. Eng., B 2015, 193, 97-104. doi:10.1016/j.mseb.2014.11.011

39. Liang, S.; Zhu, J.; Wang, C.; Yu, S.; Bi, H.; Liu, X.; Wang, X. Appl. Surf. Sci. 2014, 292, 278-284. doi:10.1016/j.apsusc.2013.11.130
40. Mansha, M.; Qurashi, A.; Ullah, N.; Bakare, F. O.; Khan, I.; Yamani, Z. H. Ceram. Int. 2016, 42, 11490-11495. doi:10.1016/j.ceramint.2016.04.035

41. Chu, J.; Wang, X.; Wang, D.; Yang, A.; Lv, P.; Wu, Y.; Rong, M.; Gao, L. Carbon 2018, 135, 95-103. doi:10.1016/j.carbon.2018.04.037

42. Lee, A.; Park, J.; Choi, K. S.; Lee, J.; Yoo, I.; Cho, I. S.; Ahn, B.; Seo, H.; Choi, J.-Y.; Yu, H. K. Carbon 2017, 125, 221-226. doi:10.1016/j.carbon.2017.09.065

43. Geng, X.; Lu, P.; Zhang, C.; Lahem, D.; Olivier, M.; Debliquy, M. Sens. Actuators, $B$, in press.

44. WHO guidelines - Air polution. http://www.who.int/airpollution/guidelines/en/ (accessed Sept 21, 2014).

45. Chen, Y.; Zhang, W.; Wu, Q. Sens. Actuators, B 2017, 242, 1216-1226. doi:10.1016/j.snb.2016.09.096

46. Tai, H.; Yuan, Z.; Zheng, W.; Ye, Z.; Liu, C.; Du, X. Nanoscale Res. Lett. 2016, 11, 130. doi:10.1186/s11671-016-1343-7

47. Zhang, D.; Jiang, C.; Liu, J.; Cao, Y. Sens. Actuators, B 2017, 247, 875-882. doi:10.1016/j.snb.2017.03.108

48. Lin, H.-H.; Wang, C.-Y.; Shih, H. C.; Chen, J.-M.; Hsieh, C.-T. J. Appl. Phys. 2004, 95, 5889-5895. doi:10.1063/1.1690114

49. Yang, H.; Li, J.; Yu, D.; Li, L. Cryst. Growth Des. 2016, 16 , 4831-4838. doi:10.1021/acs.cgd.6b00034

50. Yin, M.; Wang, F.; Fan, H.; Xu, L.; Liu, S. J. Alloys Compd. 2016, 672, 374-379. doi:10.1016/j.jallcom.2016.02.197

51. Zhang, D.; Chang, H.; Li, P.; Liu, R. J. Mater. Sci.: Mater. Electron. 2016, 27, 3723-3730. doi:10.1007/s10854-015-4214-6

52. Wang, T.; Sun, Z.; Huang, D.; Yang, Z.; Ji, Q.; Hu, N.; Yin, G.; He, D.; Wei, H.; Zhang, Y. Sens. Actuators, B 2017, 252, 284-294. doi:10.1016/j.snb.2017.05.162

53. Su, P.-G.; Yang, L.-Y. Sens. Actuators, B 2016, 223, 202-208. doi:10.1016/j.snb.2015.09.091

54. Singh, G.; Choudhary, A.; Haranath, D.; Joshi, A. G.; Singh, N.; Singh, S.; Pasricha, R. Carbon 2012, 50, 385-394. doi:10.1016/j.carbon.2011.08.050

55. Wang, Z.; Zhang, Y.; Liu, S.; Zhang, T. Sens. Actuators, B 2016, 222, 893-903. doi:10.1016/j.snb.2015.09.027

56. Tammanoon, N.; Wisitsoraat, A.; Sriprachuabwong, C.; Phokharatkul, D.; Tuantranont, A.; Phanichphant, S.; Liewhiran, C. ACS Appl. Mater. Interfaces 2015, 7, 24338-24352. doi:10.1021/acsami.5b09067

57. Liu, Z.; Yu, L.; Guo, F.; Liu, S.; Qi, L.; Shan, M.; Fan, X. Appl. Surf. Sci. 2017, 423, 721-727. doi:10.1016/j.apsusc.2017.06.160

58. Jiang, X.; Tai, H.; Ye, Z.; Yuan, Z.; Liu, C.; Su, Y.; Jiang, Y. Mater. Lett. 2017, 186, 49-52. doi:10.1016/j.matlet.2016.08.010

59. Zhang, B.; Liu, G.; Cheng, M.; Gao, Y.; Zhao, L.; Li, S.; Liu, F.; Yan, X.; Zhang, T.; Sun, P.; Lu, G. Sens. Actuators, B 2018, 261, 252-263. doi:10.1016/j.snb.2018.01.143

60. Zhang, B.; Cheng, M.; Liu, G.; Gao, Y.; Zhao, L.; Li, S.; Wang, Y.; Liu, F.; Liang, X.; Zhang, T.; Lu, G. Sens. Actuators, B 2018, 263, 387-399. doi:10.1016/j.snb.2018.02.117

61. Liu, S.; Wang, Z.; Zhang, Y.; Li, J.; Zhang, T. Sens. Actuators, $B$ 2016, 228, 134-143. doi:10.1016/j.snb.2016.01.023

62. Zhang, H.; Feng, J.; Fei, T.; Liu, S.; Zhang, T. Sens. Actuators, $B$ 2014, 190, 472-478. doi:10.1016/j.snb.2013.08.067

63. Liu, S.; Yu, B.; Zhang, H.; Fei, T.; Zhang, T. Sens. Actuators, B 2014, 202, 272-278. doi:10.1016/j.snb.2014.05.086 
64. Piloto, C.; Shafiei, M.; Khan, H.; Gupta, B.; Tesfamichael, T.; Motta, N. Appl. Surf. Sci. 2018, 434, 126-133.

doi:10.1016/j.apsusc.2017.10.152

65. Liu, J.; Li, S.; Zhang, B.; Wang, Y.; Gao, Y.; Liang, X.; Wang, Y.; Lu, G. J. Colloid Interface Sci. 2017, 504, 206-213. doi:10.1016/j.jcis.2017.05.053

66. Luo, Y.; Zhang, C.; Zheng, B.; Geng, X.; Debliquy, M. Int. J. Hydrogen Energy 2017, 42, 20386-20397. doi:10.1016/j.ijhydene.2017.06.066

67. Li, J.; Liu, X.; Sun, J. Ceram. Int. 2016, 42, 2085-2090. doi:10.1016/j.ceramint.2015.09.134

68. Liu, X.; Sun, J.; Zhang, X. Sens. Actuators, B 2015, 211, 220-226. doi:10.1016/j.snb.2015.01.083

69. Liu, X.; Cui, J.; Sun, J.; Zhang, X. RSC Adv. 2014, 4, 22601-22605. doi:10.1039/c4ra02453b

70. Fujishima, A.; Honda, K. Nature 1972, 238, 37-38. doi:10.1038/238037a0

71. Low, F. W.; Lai, C. W.; Abd Hamid, S. B. Ceram. Int. 2017, 43, 625-633. doi:10.1016/j.ceramint.2016.09.205

72. Mor, G. K.; Carvalho, M. A.; Varghese, O. K.; Pishko, M. V.; Grimes, C. A. J. Mater. Res. 2004, 19, 628-634. doi:10.1557/jmr.2004.19.2.628

73. Li, X.; Zhao, Y.; Wang, X.; Wang, J.; Gaskov, A. M.; Akbar, S. A. Sens. Actuators, B 2016, 230, 330-336. doi:10.1016/j.snb.2016.02.069

74. Ye, Z.; Tai, H.; Xie, T.; Su, Y.; Yuan, Z.; Liu, C.; Jiang, Y. Mater. Lett. 2016, 165, 127-130. doi:10.1016/j.matlet.2015.11.129

75. Ye, Z.; Tai, H.; Guo, R.; Yuan, Z.; Liu, C.; Su, Y.; Chen, Z.; Jiang, Y. Appl. Surf. Sci. 2017, 419, 84-90. doi:10.1016/j.apsusc.2017.03.251

76. Fan, G.; Wang, Y.; Hu, M.; Luo, Z.; Li, G. Meas. Sci. Technol. 2011, 22, 045203. doi:10.1088/0957-0233/22/4/045203

77. Gurlo, A. Nanoscale 2011, 3, 154-165. doi:10.1039/c0nr00560f

78. Lin, Q.; Li, Y.; Yang, M. Sens. Actuators, B 2012, 173, 139-147. doi:10.1016/j.snb.2012.06.055

79. Bo, Z.; Yuan, M.; Mao, S.; Chen, X.; Yan, J.; Cen, K. Sens. Actuators, B 2018, 256, 1011-1020. doi:10.1016/j.snb.2017.10.043

80. Yang, W.; Wan, P.; Zhou, X.; Hu, J.; Guan, Y.; Feng, L. ACS Appl. Mater. Interfaces 2014, 6, 21093-21100. doi:10.1021/am505949a

81. Meng, H.; Yang, W.; Ding, K.; Feng, L.; Guan, Y. J. Mater. Chem. A 2015, 3, 1174-1181. doi:10.1039/c4ta06024e

82. Li, X.; Wang, J.; Xie, D.; Xu, J.; Dai, R.; Xiang, L.; Zhu, H.; Jiang, Y. Sens. Actuators, B 2015, 221, 1290-1298. doi:10.1016/j.snb.2015.07.102

83. Mu, H.; Zhang, Z.; Zhao, X.; Liu, F.; Wang, K.; Xie, H. Appl. Phys. Lett. 2014, 105, 033107. doi:10.1063/1.4890583

84. Su, P.-G.; Peng, S.-L. Talanta 2015, 132, 398-405. doi:10.1016/j.talanta.2014.09.034

85. Gu, F.; Nie, R.; Han, D.; Wang, Z. Sens. Actuators, B 2015, 219, 94-99. doi:10.1016/j.snb.2015.04.119

86. Dong, Y.-I.; Zhang, X.-f.; Cheng, X.-I.; Xu, Y.-m.; Gao, S.; Zhao, H.; Huo, L.-h. RSC Adv. 2014, 4, 57493-57500. doi:10.1039/c4ra10136g

87. Yang, Y.; Tian, C.; Wang, J.; Sun, L.; Shi, K.; Zhou, W.; Fu, H. Nanoscale 2014, 6, 7369-7378. doi:10.1039/c4nr00196f

88. Zhang, C.; Geng, X.; Olivier, M.; Liao, H.; Debliquy, M. Ceram. Int. 2014, 40, 11427-11431. doi:10.1016/j.ceramint.2014.03.109

89. Zhang, C.; Van Overschelde, O.; Boudiba, A.; Snyders, R.; Olivier, M.-G.; Debliquy, M. Mater. Chem. Phys. 2012, 133, 588-591. doi:10.1016/j.matchemphys.2012.01.116
90. Jie, X.; Zeng, D.; Zhang, J.; Xu, K.; Wu, J.; Zhu, B.; Xie, C. Sens. Actuators, B 2015, 220, 201-209. doi:10.1016/j.snb.2015.05.047

91. Vasilopoulou, M.; Palilis, L. C.; Georgiadou, D. G.; Douvas, A. M.; Argitis, P.; Kennou, S.; Sygellou, L.; Papadimitropoulos, G.; Kostis, I.; Stathopoulos, N. A.; Davazoglou, D. Adv. Funct. Mater. 2011, 21 , 1489-1497. doi:10.1002/adfm.201002171

92. Feng, Q.; Li, X.; Wang, J.; Gaskov, A. M. Sens. Actuators, B 2016, 222, 864-870. doi:10.1016/j.snb.2015.09.021

93. Kumar, R.; Kushwaha, N.; Mittal, J. Sens. Actuators, B 2017, 244, 243-251. doi:10.1016/j.snb.2016.12.111

94. Zhang, J.; Zeng, D.; Zhao, S.; Wu, J.; Xu, K.; Zhu, Q.; Zhang, G.; Xie, C. Phys. Chem. Chem. Phys. 2015, 17, 14903-14911. doi:10.1039/c5cp01987g

95. Zhang, J.; Wu, J.; Wang, X.; Zeng, D.; Xie, C. Sens. Actuators, B 2017, 243, 1010-1019. doi:10.1016/j.snb.2016.12.062

96. Su, P.-G.; Chen, F.-Y.; Wei, C.-H. Sens. Actuators, B 2018, 254 , 1125-1132. doi:10.1016/j.snb.2017.07.199

97. Ye, Z.; Tai, H.; Xie, T.; Yuan, Z.; Liu, C.; Jiang, Y. Sens. Actuators, B 2016, 223, 149-156. doi:10.1016/j.snb.2015.09.102

98. Anasthasiya, A. N. A.; Kishore, K. R.; Rai, P. K.; Jeyaprakash, B. G. Sens. Actuators, B 2018, 255, 1064-1071. doi:10.1016/j.snb.2017.08.148

99. Huang, Q.; Zeng, D.; Li, H.; Xie, C. Nanoscale 2012, 4, 5651-5658. doi:10.1039/c2nr31131c

100.Srivastava, V.; Jain, K. Mater. Lett. 2016, 169, 28-32. doi:10.1016/j.matlet.2015.12.115

101.Chen, N.; Li, X.; Wang, X.; Yu, J.; Wang, J.; Tang, Z.; Akbar, S. A. Sens. Actuators, B 2013, 188, 902-908. doi:10.1016/j.snb.2013.08.004

102.Zhang, D.; Chang, H.; Li, P.; Liu, R.; Xue, Q. Sens. Actuators, B 2016, 225, 233-240. doi:10.1016/j.snb.2015.11.024

\section{License and Terms}

This is an Open Access article under the terms of the Creative Commons Attribution License (http://creativecommons.org/licenses/by/4.0). Please note that the reuse, redistribution and reproduction in particular requires that the authors and source are credited.

The license is subject to the Beilstein Journal of Nanotechnology terms and conditions: (https://www.beilstein-journals.org/bjnano)

The definitive version of this article is the electronic one which can be found at: $\underline{\text { doi:10.3762/bjnano.9.264 }}$ 